\title{
Detection of physical hazards in soil profiles using quantitative soil physical quality assessment in the Pannonian basin, Eastern Austria**
}

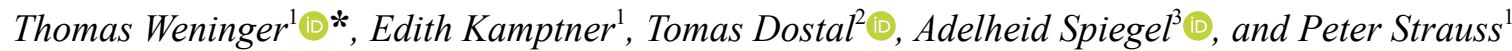 \\ ${ }^{1}$ Institute for Land and Water Management, Federal Agency of Water Management, Pollnbergstraße 1, 3252 Petzenkirchen, Austria \\ ${ }^{2}$ Faculty of Civil Engineering, Department of Landscape Water Conservation, Czech Technical University Prague, Thákurova 7 , \\ 16629 Prague 6, Czech Republic \\ ${ }^{3}$ Institute for Soil Health and Plant Nutrition, Austrian Agency for Health and Food Safety, Spargelfeldstraße 191, 1220 Vienna, Austria
}

Received October 1, 2020; accepted November 13, 2020

\begin{abstract}
Reliable estimations of soil physical quality provide valuable information for the evaluation and advancement of agricultural soil management strategies. In the agriculturally highly productive Pannonian basin in Eastern Austria, little emphasis has been placed on the determination of soil physical quality and corresponding soil degradation risks. Nevertheless, ongoing climate change, especially prolonged drought periods and higher rainfall intensity, will raise the need for appropriate soil management strategies. Soil physical quality was therefore assessed in nine soil profiles in a long-term tillage experiment which has been in operation since 1988 in Eastern Austria. Soil samples from depths of between 2 and $37 \mathrm{~cm}$ and under three different tillage systems (conventional, reduced and minimal tillage) were analysed for various indicators of soil physical quality. The resulting classifications of soil physical quality in the different profiles were compared qualitatively and quantitatively together with an estimation concerning the representativeness of the soil physical quality indicators used. The outcomes showed severe soil compaction under all tillage treatments and slight improvements in soil physical quality marginally above the working depth for the different treatments. Additionally, conversion to conservation tillage led to less pronounced improvements in soil physical quality under Pannonian conditions than have been reported in more humid climates.

Keyw ord s: tillage intensity, soil compaction, soil water balance, soil management
\end{abstract}

*Corresponding author e-mail: thomas.weninger@baw.at **This work was partially supported from the projects 'Catch-C' (FP7-KBBE-2011-5), which is co-funded by the European Commission, 'Development of automated tools for the optimal monitoring of the erosion of agricultural land using remote sensing methods' (QK1720289, 2017-2019) and 'Shui' (773903), which is co-funded by the European Commission within H2020-EU.3.2.1.1.

\section{INTRODUCTION}

In agriculturally dominated landscapes, a major part of the land and soil is intensively managed by human activities. The applied soil management strategies greatly influence the capacity of the soil to regulate many parameters, including the water balance, sediment transport, plant growth capacity, biodiversity, and climate change resilience on a field and landscape scale. The physical constitution or quality of soil forms the basis for its ability to sustainably provide these manifold functions to ecosystems which benefit our civilization (McKenzie et al., 2011). A comprehensive assessment of the actual soil physical quality (SPQ) allows for interpretations based on the present risks for soil functionality and the evaluation of different soil management strategies. Several SPQ-indicators (SPQIs) are available which account for certain soil characteristics or soil degradation risks.

A frequently formulated aim in SPQ research has been to use indicators which represent a potentially high value of still reliable information which is possibly expressed by strong correlations to a high number of other SPQ characteristics (Koureh et al., 2020). As most scalar SPQIs are linked to certain soil characteristics, a combination of SPQIs allows for a detailed detection of soil degradation risks as well as an overall assessment of SPQ (Iovino et al., 2016). Furthermore, the appropriate SPQIs account for the dynamic nature of the soil, especially with regard to

(C) 2020 Institute of Agrophysics, Polish Academy of Sciences 
temporal changes in the physical constitution of the soil e.g. following soil management changes. Castellini et al. (2019), for example, evaluated five SPQIs using applied multivariate analysis techniques. The authors demonstrated strong correlations between several SPQIs and emphasized relative field capacity (RFC) as a key soil physical variable, especially for assessments of the effect of tillage. Koureh et al. (2020) linked SPQ measurements with the growth characteristics of wheat and emphasized the suitability of the SPQI $S_{\text {inf }}$, which represents the slope of the water retention function at the air inflection point and is a widely used SPQI, (Dexter and Czyż, 2007) and also its relationship to wheat growth.

The effect of conservation tillage or reduced tillage on SPQ was analysed frequently under different climate and soil conditions. In the humid regions of Scandinavia and north-western France which have frequent rain deficits in summer, higher water reserves in dry periods and a greater macroporosity have been found under conservation tillage than under conventional tillage (e.g. Rasmussen, 1999; Bottinelli et al., 2013). However, in the humid climate of northern and western Europe, the application of conservation or no-tillage may promote undesirable anaerobic conditions in poorly drained soils, while it tends to be beneficial for water conservation and for macroporosity in the arid and semi-arid conditions of southern Europe (Moreno et al., 1996; Fernández-Ugalde et al., 2009). By contrast, on a clay soil in arid southern Italy, the hydraulic conductivity and the porosity were lower under conservation tillage than under conventional tillage due to a loss of pore volume (Castellini and Ventrella, 2012; Piccoli et al., 2020). Sandén et al. (2018) integrated the outcomes from 251 European long-term experiments, and found a higher abundance of earthworms, higher bulk densities and higher SOC concentration than for conventional tillage under non-inversion tillage (mainly) for the $0-30 \mathrm{~cm}$ soil layer.

In Central Europe, and in particular under the conditions of the Pannonian climate, the impact of reduced tillage on SPQ has received very little attention, even though the region contributes considerably to the agricultural productivity of Central Europe. In this area, the choice of effective tillage methods for soil water conservation has become increasingly important as future climate scenarios predict an increase in drought and heat stress periods in the sensitive stages of plant development (Thaler et al., 2012; Olesen et al., 2011). Most comparably, Schlüter et al. (2018) found progressing compaction conditions with reduced tillage due to the lack of deep rooting crops and dry periods which caused earthworm inactivity in a semi-arid region in Germany with silt-dominated soil.

The aim of this study was the detailed assessment of the SPQ with special emphasis on the Pannonian climate conditions of the Marchfeld region in Austria, an important agricultural area in Central Europe. We measured and calculated multiple SPQIs which were hypothesized to allow for the precise detection of critical SPQ conditions and soil physical degradation hazards in different soil profiles. The investigated field trial was managed under three different tillage systems continuously over a period of 24 years, which also allowed for the determination of the medium-term effects of changes in soil management on SPQ.

\section{MATERIALS AND METHODS}

The Fuchsenbigl experimental site is located in the Pannonian lowlands, a transition region between the semi-humid western European climate zone and the continental eastern European climate zone (Thaler et al., 2012). The region is characterized by hot, dry summers and cold winters with little snowfall. The mean annual temperature between 1988 and 2012 was $10.1^{\circ} \mathrm{C}$, and the mean annual precipitation was $583 \mathrm{~mm}$. The soil type is a Haplic Chernozem according to the FAO classification. As the terrain is flat, lateral water erosion did not occur and no relevant wind erosion was observed at the sites. Crop rotation was cereal-based, typically consisting of winter wheat, sugar beet, spring barley and maize. Three different tillage treatments were applied continuously since 1988 (Spiegel et al., 2007):

- Conventional tillage (CT): Stubble processing by wing share cultivator after harvest (brand: Regent, $23 \mathrm{~cm}$ wing width, overlapping construction), tillage before seeding by mouldboard plough (brand: Vogel and Noot, $25-30 \mathrm{~cm}$ working depth), seedbed preparation by seedbed combination (brand: Pettner, equipped with rollers and tine harrow with working depth 5-8 cm).

- Reduced tillage (RT): Primary tillage and stubble processing by wing share cultivator (15 cm working depth), seedbed preparation with seedbed combination.

- Minimum tillage (MT): Sowing either by rotary driller (brand: Horsch) with no further treatment or preparation by rotary tiller before sowing (5-8 cm working depth).

All crop residues remained on the field. The area had already been used as arable land and conventional tillage was the standard soil management procedure before the experiment commenced. In the experiment, the different treatments were applied on plot strips arranged in a $3 \times 3$ randomized block design. Each plot covered an area of $60 \times 12 \mathrm{~m}$, including a buffer of $1 \mathrm{~m}$ along each border.

Soil samples were taken in March 2001 and August 2012 for each treatment and at four depths: 2-7, 10-15, 15-20 and $32-37 \mathrm{~cm}$. In 2001, a transect of three soil profiles was analysed in the central block of the field. Closely adjacent to these profile points, three corresponding profiles were examined in 2012 to account for temporal changes (the spatial notation for both is transect South, tsS). Additionally, a transect of three profiles with a longitudinal distance of $50 \mathrm{~m}$ to the former was sampled to account for spatial variability (transect North, tsN). Undisturbed soil samples $\left(\mathrm{n}=5\right.$, steel sampling cores with a volume of $200 \mathrm{~cm}^{3}$ ) were 
used to determine the bulk density, the soil water retention characteristics (WRC) and saturated hydraulic conductivity $\left(\mathrm{K}_{\mathrm{s}}\right)$. Bulk soil samples $(\mathrm{n}=1$, mixed sample) were taken from the immediate surroundings of the cores by using a shovel. These disturbed samples were used for the analysis of soil texture, soil organic carbon (SOC) and particle density.

The soil texture was analysed by combined wet sieving and sedimentation. The falling head method was applied to measure $\mathrm{K}_{\mathrm{s}}$ in the saturated undisturbed soil cores and bulk density (BD) was analysed by drying the soil core samples at $105^{\circ} \mathrm{C}$ (Dane and Topp, 2002). Subsequently, the saturated volumetric water content $\left(\theta_{\mathrm{s}}\right)$ was calculated as the difference between the mass of the saturated soil core and the mass of the oven dried soil core, assuming $\rho_{\text {water }}=$ $1.00 \mathrm{~g} \mathrm{~cm}^{-3}$. Even though it may be denoted as a chemical characteristic, SOC is a major attribute of soil quality, which is closely linked to the physical properties of the soil and sustains a range of soil functions (Merante et al., 2017). The concentration of SOC was determined by dry combustion and the subtraction of the inorganic carbon from the total carbon.

Several indicators of SPQ are based on an analysis of the WRC, the relationship between the volumetric soil water content $\theta$ and the matric potential or soil water head $h$. The points of WRC were measured with a pressure plate apparatus at the soil water head levels of 10, 30, 60, 100, $300,800,3000$ and $15000 \mathrm{~cm}$. A continuous non-linear function (van Genuchten, 1980) was fitted to the resulting data pairs as a basis for the calculation of the corresponding SPQ-indicators. In particular, field capacity (FC) is a determinant for several SPQIs related to the WRC, but the underlying concept and the measurement methods are not clearly defined (Assouline and Or, 2014; Turek et al., 2019). Hence, we used a dynamic approach to calculate FC which was found to yield plausible results for a wide range of soil types (Twarakavi et al., 2009; Turek et al., 2019).

In this study, a variety of indicators were chosen for in-depth analyses (Table 1). In addition to SPQIs which were measured directly $\left(\mathrm{BD}, \mathrm{K}_{\mathrm{s}}, \theta_{\mathrm{s}}\right.$, SOC) or directly related to a range of pore sizes such as plant water capacity (PAWC) and RFC, two SPQIs based on more complex concepts were calculated: The soil physical quality index $\mathrm{S}_{\mathrm{inf}}$, the slope of the WRC at its inflection point, was established and found to be related to multiple soil physical characteristics (Dexter and Czyż, 2007). A rather new and promising approach which was used is the relative air-water energy index $\left(\mathrm{AW}_{\mathrm{r}}\right.$; Armindo and Wendroth, 2016, 2019). It is calculated as the fraction of the integrated aeration energy (indicates the integrated gravitational potential of drainable water between saturation and FC) and the integrated water retention energy between $\mathrm{FC}$ and the permanent wilting point $(\mathrm{h}=15000 \mathrm{~cm})$.
Additionally, several thresholds for certain SPQIs were presented in literature or derived considering the required soil functionality (Table 1). All SPQIs were calculated for each sample separately to allow for a detailed assessment of the SPQ and degradation issues within the single soil profiles. The work of Reynolds et al. (2009) may be seen as a key source for SPQ assessment based on thresholds and the presented limit values therein were widely used, evaluated and slightly modified (e.g. Castellini et al., 2019). These thresholds represent either the limits for unaffected plant growth or other limits for the physical degradation of the soil and were also used in our study. For $\mathrm{K}_{\mathrm{s}}$, the thresholds were derived from official design values for high intensity precipitation (Table 1). For each SPQI, where thresholds were available, they were applied in two steps - one for a good and one for a poor SPQ. In addition, a classification of the SPQ values was conducted based on these thresholds and the range between the first and third quartiles of the samples (according to Iovino et al., 2016). If the range between the quartiles was fully on the positively connoted side of the "good" threshold, it followed that the SPQ was very good; if the median was between the two thresholds, the SPQ was good; if the median was on the negatively connoted side of the "poor" threshold, the SPQ was poor; and if the full range between the first and third quartile was on the negative side of the "poor" threshold, the SPQ was denoted as being very poor.

A statistical analysis and data visualization were performed using R. ANOVA and the post-hoc Tukey HSD test was used to detect the differences between the soil profiles $(\alpha=0.05)$. The homogeneity of variance was confirmed for all comparisons, with the exception of $\mathrm{K}_{\mathrm{s}}$ at a depth of $2-7 \mathrm{~cm}$ and $S_{\text {inf }}$ at a depth of 2-7 cm.

\section{RESULTS}

Textural classification was performed based on the measured particle-size distribution and applied according to the USDA texture triangle. Loam was the texture class found for all samples with the exception of one sample under reduced tillage (RT) at a depth of $32-37 \mathrm{~cm}$. At this location, the C-horizon, which had a higher sand content and corresponded to the textural class of Sandy Loam, was unintentionally sampled. The effects of this outlier result on soil physical quality assessment may be neglected. The means for grain size classes and their respective standard deviations (in brackets) were $43.1 \%$ (4.0) for sand, 39.9\% (2.4) for silt and $17.0 \%$ (2.3) for clay (excluding RT at a depth of $32-37 \mathrm{~cm}$ ). The soil organic carbon (SOC) concentrations were between 1.3 and 1.5 mass percent and followed slight decreasing trends with soil depth (Fig. 1). This trend was not observable in conventional tillage (CT) due to frequent soil turnover. Only the topmost layer under RT treatment showed a higher SOC content of around 2\% in all experiments and the samples from the lowest depth 
Table 1. List of soil physical quality indicators (SPQI) used with a short description and limits for soil physical functionality, if available

\begin{tabular}{|c|c|c|}
\hline SPQI & Limit values & Description \\
\hline$\theta_{\mathrm{s}}\left(\mathrm{cm}^{3} \mathrm{~cm}^{-3}\right)$ & - & $\begin{array}{l}\text { volumetric soil water content at saturation (interchangeably } \\
\text { with total porosity) }\end{array}$ \\
\hline $\mathrm{BD}\left(\mathrm{g} \mathrm{cm}^{-3}\right)$ & $\begin{array}{l}\mathrm{BD}>1.3 \ldots \text { potential yield losses } \\
0.9<\mathrm{BD}<1.2 \ldots \text { optimal range }\end{array}$ & $\begin{array}{l}\text { bulk density; } \mathrm{BD}=\text { mass of solid soil material / volume of } \\
\text { soil in field condition }\end{array}$ \\
\hline$\theta_{\mathrm{FC}}\left(\mathrm{cm}^{3} \mathrm{~cm}^{-3}\right)$ & - & $\begin{array}{l}\theta \text { at field capacity, calculated according to Twarakavi et al. } \\
\text { (2009) }\end{array}$ \\
\hline $\mathrm{AC}\left(\mathrm{cm}^{3} \mathrm{~cm}^{-3}\right)$ & $\begin{array}{l}\mathrm{AC}>0.1 \text { for unaffected plant growth, } \\
0.16<\mathrm{AC}<0.24 \text { optimal }\end{array}$ & air capacity, $\mathrm{AC}=\mathrm{TP}-\theta_{\mathrm{FC}}$ \\
\hline RFC (-) & $\begin{array}{l}\text { RFC }<0.6 \ldots \text { limiting water supply, } \\
0.6<\mathrm{RFC}<0.7 \ldots \text { optimal, } \\
\mathrm{RFC}>0.8 \ldots \text { aeration deficit }\end{array}$ & relative field capacity, $\mathrm{RFC}=\theta_{\mathrm{FC}} / \theta_{\mathrm{s}} ;$ Reynolds et al. (2009) \\
\hline PAWC $\left(\mathrm{cm}^{3} \mathrm{~cm}^{-3}\right)$ & PAWC $>0.2 \ldots$ optimal & plant available water capacity, $\mathrm{PAWC}=\theta_{\mathrm{FC}}-\theta_{\mathrm{h}=15000 \mathrm{~cm}}$ \\
\hline cumPAWC (cm) & - & $\begin{array}{l}\text { cumulated PAWC over observed profile depth, measure for } \\
\text { plant available water reservoir }\end{array}$ \\
\hline $\mathrm{K}_{\mathrm{s}}\left(\mathrm{cm} \mathrm{d}^{-1}\right)$ & $\begin{array}{l}\text { based on official reference values for } \\
\text { 15-min-heavy rainfall in the project region } \\
\text { and annuities } \mathrm{T} \text {; medium degradation: } \\
\mathrm{K}_{\mathrm{s}}<206 \mathrm{~cm} \mathrm{~d}^{-1}(\mathrm{~T}=10 \mathrm{a}) \text {, severe } \\
\text { degradation: } \mathrm{K}_{\mathrm{s}}<85 \mathrm{~cm} \mathrm{~d}^{-1}(\mathrm{~T}=1 \mathrm{a})\end{array}$ & saturated hydraulic soil conductivity \\
\hline $\operatorname{SOC}\left(\mathrm{g} \mathrm{g}^{-1}\right)$ & $\begin{array}{l}<0.01 \mathrm{~g} \mathrm{~g}^{-1} \ldots \text { risk of structure loss due } \\
\text { to tillage or weather }\end{array}$ & Soil organic carbon concentration \\
\hline $\mathrm{S}_{\mathrm{inf}}(-)$ & $\begin{array}{l}\mathrm{S}_{\text {inf }}>0.05 \ldots \text { optimal } \\
\mathrm{S}_{\text {inf }}<0.035 \ldots \text { poor }\end{array}$ & $\begin{array}{l}\text { Dexter's SPQ-index, slope } \\
\mathrm{S}_{\text {inf }}=-\mathrm{n}\left(\theta_{\mathrm{s}}-\theta_{\mathrm{r}}\right)\left((2 \mathrm{n}-1) /(\mathrm{n}-1)^{1 / \mathrm{n}-2}\right) \\
\text { Dexter and Czyż }(2007), \text { Koureh et al. }(2020)\end{array}$ \\
\hline $\mathrm{AW}_{\mathrm{r}}(-)$ & - & $\begin{array}{l}\text { relative air-water energy index, Armindo and Wendroth } \\
(2016,2019) \text {, calculated based on } \mathrm{WRC}=\mathrm{pF}(\theta) \text { where } \\
\mathrm{pF}=\log _{10}|\mathrm{~h}|\end{array}$ \\
\hline
\end{tabular}

$(32-37 \mathrm{~cm})$, in some locations, had lower SOC concentrations of $0.80-1.22 \%$ in the transect south (tsS). As SOC is a determinant of several soil physical properties (Loveland and Webb, 2003) this deviation had to be considered in further interpretations, even though the significance of these patterns could not be proven due to the small sample size.

All SPQI values followed a normal distribution except for the saturated hydraulic conductivity $\left(\mathrm{K}_{\mathrm{s}}\right)$ and relative air-water energy index $\left(\mathrm{AW}_{\mathrm{r}}\right)$ which clearly followed a lognormal distribution. Therefore, the latter were transformed by a common logarithm before further analysis. The bulk density $(\mathrm{BD})$ and saturated water content $\left(\theta_{\mathrm{s}}\right)$ were closely correlated and both represent soil porosity (Table 2). In the determination process, only the saturation of soil cores is a source of possible bias. In order to omit such a bias, BD was used for further interpretation. The indicators RFC and AC both describe soil aeration and were closely correlated. The relative field capacity (RFC) was found to be the more distinctive indicator for SPQ in previous studies, hence air capacity (AC) was not discussed further (Castellini et al., 2019). The highest average correlation scores were found for $\theta_{\mathrm{s}}, \mathrm{BD}$, and $\mathrm{AC}$, while medium scores were found for

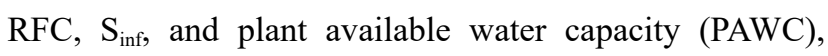
while $\log _{10}\left(\mathrm{~K}_{\mathrm{s}}\right)$ and $\log _{10}\left(\mathrm{AW}_{\mathrm{r}}\right)$ revealed the lowest means of absolute correlation coefficients between SPQIs.

Under RT treatment, the cumulated PAWC in the soil profile down to $40 \mathrm{~cm}$ was found to be lower than the result obtained under the other treatments even though the absolute differences were small (Fig. 2). In tsS which was analysed in 2001 and 2012, a decrease was observed over time. Nevertheless, all of the values were above the lower threshold for ideal plant growth of $0.20 \mathrm{~cm}^{3} \mathrm{~cm}^{-3}$ (Reynolds et al., 2009).

The median $\mathrm{K}_{\mathrm{s}}$ was below the lower critical limit in 21 out of 36 cases, that means that the maximum annual 15-min precipitation cannot fully percolate into the soil (Fig. 3). In particular, CT and minimal tillage (MT) treatments showed values that, in some cases, were far below the threshold in the uppermost soil depths, which are the main determinant for the short-term infiltration capacity. The highest conductivity values in relation to the tillage treatment were found at depths of 20-25 and 32-37 cm for CT ( 2 out of 3 experiments) and at $2-7 \mathrm{~cm}$ for RT. The MT treatment showed inhomogeneous patterns with depth and 


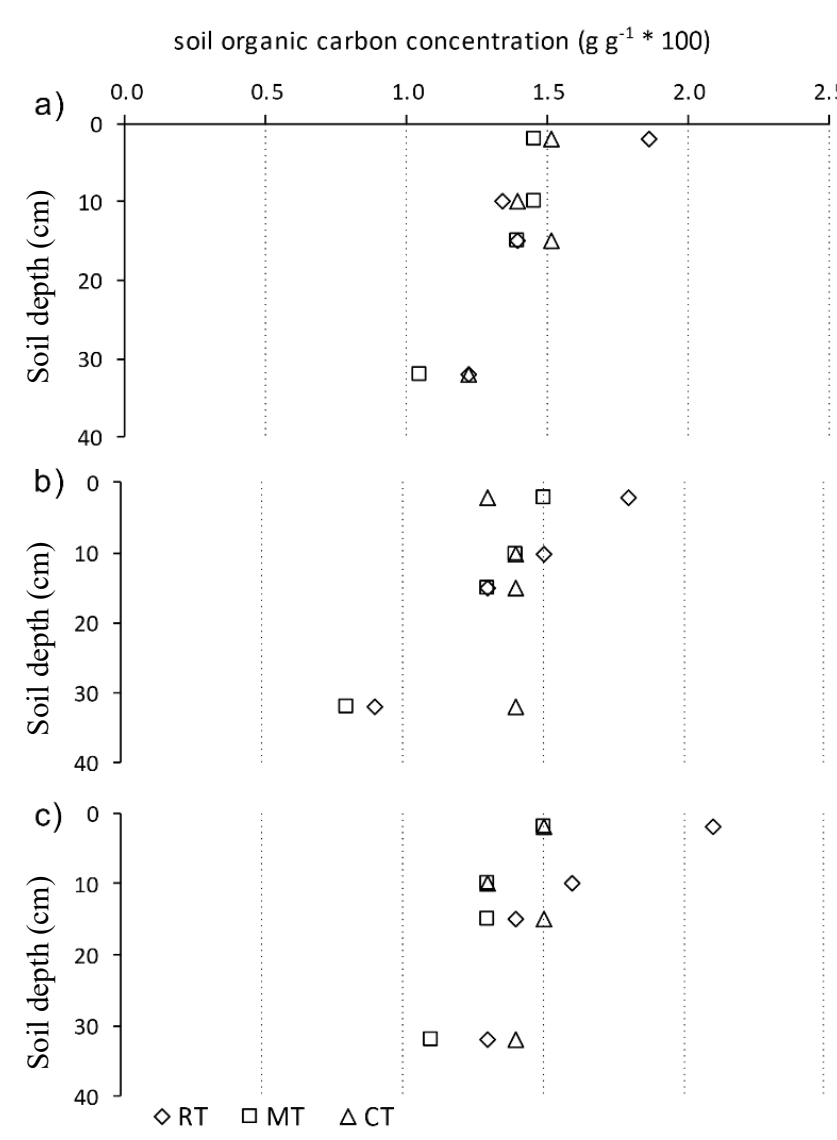

Fig. 1. Soil organic carbon concentration in the observed soil profiles. a) transect South, 2001; b) transect South, 2012; c) transect North, 2012. Symbols used: square is minimal tillage, diamond is reduced tillage, triangle is conventional tillage.

between sampling runs. For 10 out of 12 samples, the highest fraction of the samples where medians undershot the lower conductivity threshold was found under MT.

By contrast, MT had the highest number of samples in the optimal range of $\mathrm{S}_{\mathrm{inf}}$ ( 5 out of 12 medians) which is assigned above the value of 0.05 (Dexter and Czyż, 2007). Furthermore, only one sample showed an $\mathrm{S}_{\text {inf }}$ - value below the lower threshold of 0.035 indicating severe soil degradation. A distinct decrease in $\mathrm{S}_{\text {inf }}$ from the 2-7 to $10-15 \mathrm{~cm}$ depth range and partly in the $20-25 \mathrm{~cm}$ depth range was observed under conservation tillage treatments RT and MT. An increase in $S_{\text {inf }}$ could be observed in CT from 2001 to 2012 while the top layers of RT and MT showed a slight decrease (tsS). Results for $\mathrm{AW}_{\mathrm{r}}$ showed a decrease of SPQ from $2-5 \mathrm{~cm}$ down to $20-25 \mathrm{~cm}$ and a systematic increase from 2001 to 2012 in tsS. The conservation tillage treatments RT and MT had a rather constant $\mathrm{AW}_{\mathrm{r}}$ over the depth range examined with a low degree of variability. A qualitative assessment of SPQ from $\mathrm{AW}_{\mathrm{r}}$ was not possible due to the lack of reference data and thresholds. No further systematic patterns in relation to depth, treatment or sampling runs were found.

For nearly all soil samples (94\%), BD was above the upper threshold of $1.3 \mathrm{~g} \mathrm{~cm}^{-3}$ (Fig. 4) which indicates the potential yield losses due to soil compaction and a lack of aeration. Most distinctively, CT had the lowest BD at the 20-25 cm depth. The conservation tillage treatments showed comparably low BD near the surface but very high values between 10 and $25 \mathrm{~cm}$, mainly above $1.5 \mathrm{~g} \mathrm{~cm}^{-3}$. Also, most observed values of RFC were above the threshold for the risk of periodic anaerobiosis (Reynolds et al., 2009; Castellini et al., 2019). The differences between treatments were not significant in most cases, hence, no systematic pattern could be detected.

\section{DISCUSSION}

The correlations between different indicators for SPQ agreed with previous findings. Indicators like air capacity (AC), macro-porosity and relative field capacity (RFC) are closely correlated and represent the largest fraction of soil pores, they may be used interchangeably for the detection of the aeration limitation (Castellini et al., 2019). From the SPQIs used herein, RFC and $\mathrm{S}_{\text {inf }}$ were assigned given the highest value assignments in several publications (Dexter and Czyż, 2007; Castellini et al., 2019; Koureh et al.,

Table 2. Correlation table for SPQ-indicators (method Pearson). Only significant correlations are given in the correlation matrix $(\alpha=0.05)$

\begin{tabular}{lcccccccc}
\hline & $\theta_{\mathrm{s}}$ & $\mathrm{BD}$ & $\mathrm{RFC}$ & $\mathrm{AC}$ & $\mathrm{PAWC}$ & $\log _{10}\left(\mathrm{AW}_{\mathrm{r}}\right)$ & $\log _{10}\left(\mathrm{~K}_{\mathrm{s}}\right)$ & $\mathrm{S}_{\text {inf }}$ \\
\hline$\theta_{\mathrm{s}}$ & 1.00 & & & & & & & \\
$\mathrm{BD}$ & -0.93 & 1.00 & & & & & & \\
$\mathrm{RFC}$ & -0.31 & 0.18 & 1.00 & & & & & \\
$\mathrm{AC}$ & 0.51 & -0.38 & -0.97 & 1.00 & & & & \\
$\mathrm{PAWC}$ & 0.65 & -0.70 & 0.44 & -0.25 & 1.00 & & & \\
$\log _{10}\left(\mathrm{AW}_{\mathrm{r}}\right)$ & -0.26 & 0.34 & -0.28 & 0.21 & -0.40 & 1.00 & & \\
$\log _{10}\left(\mathrm{~K}_{\mathrm{s}}\right)$ & 0.52 & -0.43 & -0.55 & 0.62 & & -0.22 & 1.00 & \\
$\mathrm{~S}_{\text {inf }}$ & 0.71 & -0.63 & -0.49 & 0.60 & 0.44 & 0.17 & 0.21 & 1.00 \\
mean $|\mathrm{SPQI}|$ & 0.56 & 0.51 & 0.46 & 0.51 & 0.41 & 0.27 & 0.36 & 0.46 \\
\hline
\end{tabular}




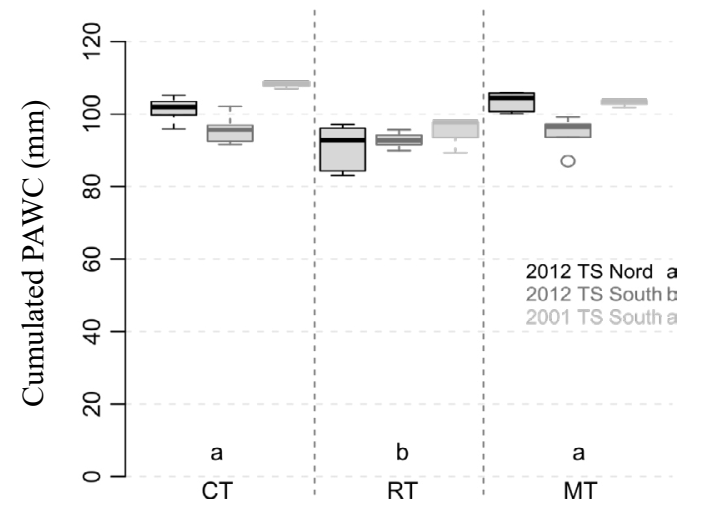

Fig. 2. Cumulated plant available water capacity (PAWC) in the upper $40 \mathrm{~cm}$ of soil, calculated based on field capacity determination using the method of Twarakavi et al. (2009). Colours indicate different measurement runs; treatments are conventional tillage (CT), reduced tillage (RT), minimal tillage (MT). Letters next to the measurement run legend and above the treatment labels indicate differences between means of the respective group (Tukey HSD test, $\alpha=0.05$ ).
2020) whereas $S_{\text {inf }}$ showed a below average correlation in our study. Furthermore, Koureh et al. (2020) linked SPQ measurements with the growth characteristics of wheat and emphasized the suitability of $\mathrm{S}_{\text {inf }}$ as an SPQI and also its relationship to wheat growth. By contrast, Lozano et al. (2016) stated that a static SPQI like RFC, plant available water capacity (PAWC), or $\mathrm{S}_{\text {inf }}$ were not useful in the prediction of soybean yield nor could they distinguish physical effects of different tillage treatments on the soil. The PAWC is widely used in studies concerning the physical changes in soil after management decisions but it also has a direct link to applications in agriculture. Nevertheless, its suitability for such applications has been questioned before (Reynolds et al., 2007; Koureh et al., 2020) and also the outcomes of the study presented herein indicates the low reliability of interpretations based on PAWC.

A great part of the measurements and comparisons with known thresholds showed severe risk for soil degradation through compaction. This vulnerability is known to exist for silt-dominated soils, like the soil sampled from
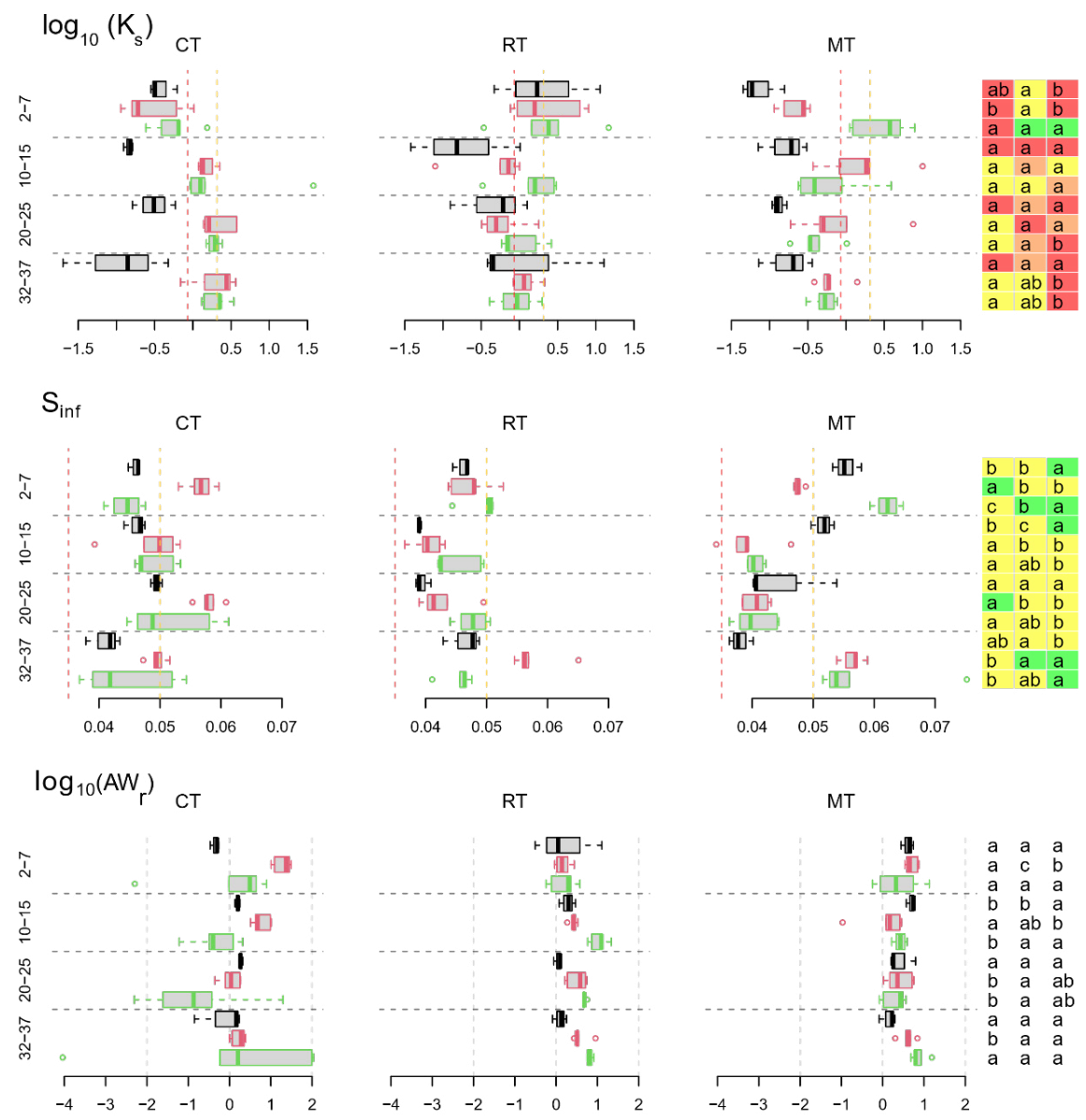

2012 TS Nord 2012 TS South 2001 TS South

Fig. 3. Comparisons of saturated hydraulic conductivity (Ks, transformed by $\log 10$ ) and $\mathrm{S}_{\text {inf }}$ in relation to soil depth (vertically splitted), tillage treatment (horizontally splitted) and sampling run (colour). The treatments are conventional tillage (CT), reduced tillage (RT), minimal tillage (MT). The coloured dashed lines mark the thresholds for moderate (yellow) and severe (red) deviations from the optimal SPQ state. Letters on the right side indicate the differences between treatments in the according row (Tukey HSD test, $\alpha=0.05$ ), colours show the SPQ classification based on threshold values where red is very poor, orange is poor, yellow is good, and green is very good. 

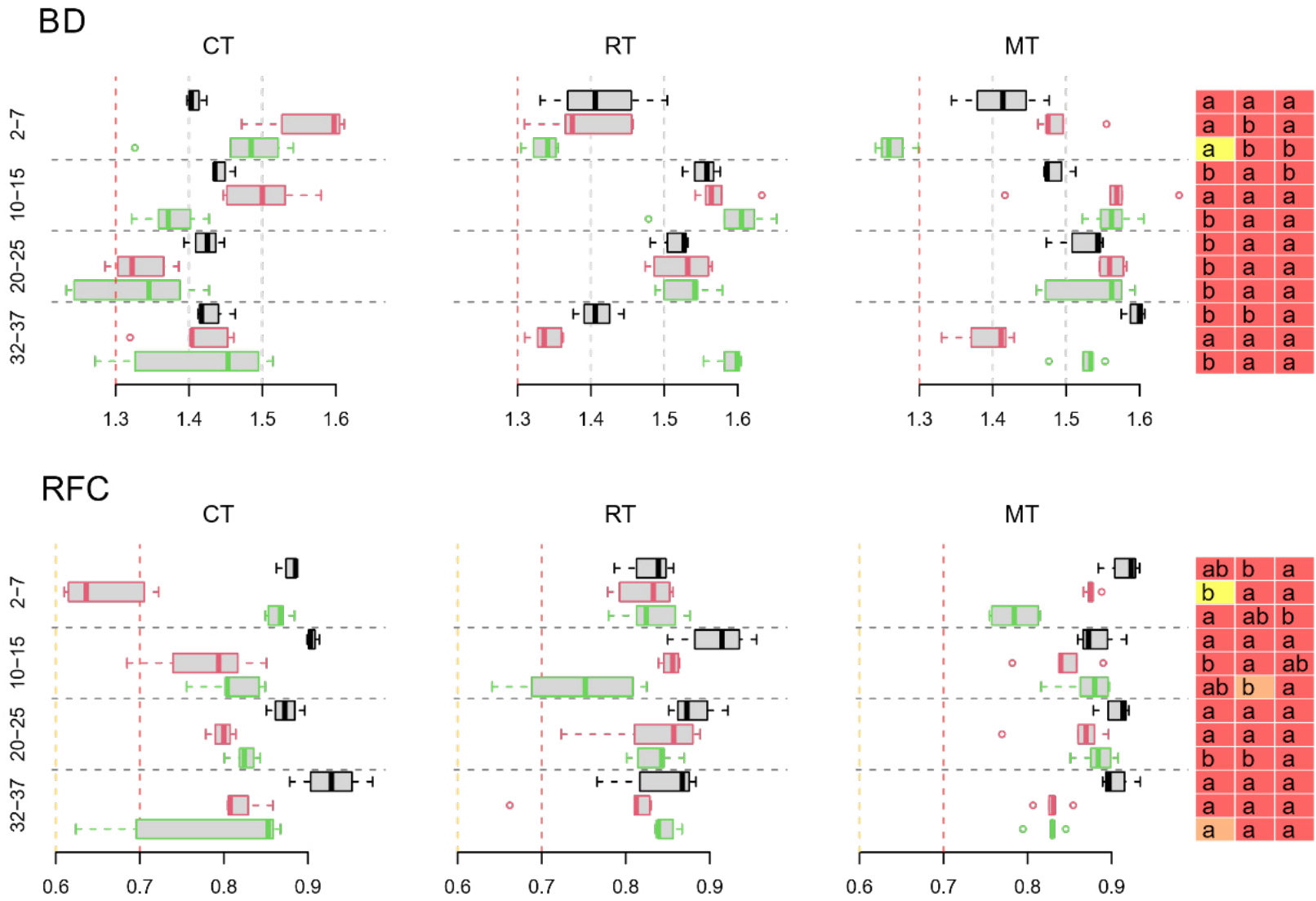

2012 TS Nord 2012 TS South 2001 TS South

Fig. 4. Comparisons of soil bulk density BD and relative field capacity RFC in relation to soil depth (vertically split), tillage treatment (horizontally split) and sampling run (colour). The treatments are conventional tillage (CT), reduced tillage (RT), minimal tillage (MT). The dashed red lines mark thresholds where exceedance indicates compaction (BD) or the lack of aeration (RFC), the yellow lines mark the lower threshold for the optimal RFC range. The letters on the right side indicate the differences between treatments in the according row (Tukey HSD test, $\alpha=0.05$ ), colours show the SPQ classification based on thresholds where red is very poor, orange is poor, and yellow is good.

the study site, the broad validity of the thresholds given in literature have been questioned sporadically (Bacher et al., 2019; Castellini et al., 2019). Nevertheless, the extent and uniformity of the threshold excess in $\mathrm{BD}, \mathrm{RFC}$, and partly saturated hydraulic conductivity $\left(\mathrm{K}_{\mathrm{s}}\right)$ endorsed the assessment of a critical SPQ state for the studied soils.

The effect of tillage operations was visible in the results for several SPQIs which showed the highest SPQ values in the lowest part of the worked soil layer. In that location, higher porosity, conductivity and lower compaction could be detected in most of the samples. Below the working depth, a typical increase in compaction signs was observed for all treatments. These outcomes were in accordance with a major part of similar studies (e.g. Rasmussen, 1999; Schlüter et al., 2018; Piccoli et al., 2020). Hence, conservation tillage with a constant working depth indicated the risk of moving soil compaction to upper layers. Nevertheless, it is commonly assumed that conservation tillage leads to an increase in soil quality, including SPQ, due to the higher degree of soil biological activity (Kahlon et al.,
2013; Sandén et al., 2018; Li et al., 2019). Several studies have shown an initial degradation and recovery after a certain establishment period for soil biology (Kay and VandenBygaart, 2002; Bottinelli et al., 2013). The average rates of improvement were found to be higher under more humid climatic conditions (e.g. Kahlon et al., 2013; Parvin et al., 2014) while under conditions comparable to the study site, the changes were less pronounced or not significant (Weninger et al., 2019). Hence, a combination with further soil conservation measures like cover crops was more promising, especially for the alleviation of compaction layers (Abdollahi et al., 2013).

Of the eight SPQIs used, four are directly linked to field capacity (FC) despite the ongoing discussion which has already led to a range of different determination approaches (e.g. Assouline and Or, 2014; de Jong van Lier, 2017; Turek et al., 2019). Most methods were developed based on extensive databases and with a comprehensible theoretical background, hence they imply comparable reliability and the decision to use a certain method is usually made 
arbitrarily. A high degree of variability between results from different methods was found (Turek et al., 2019) and this supposedly has an influence over the outcomes of SPQ assessments. Further research concerning the consequences of method choice is required to facilitate study design and the interpretation of results.

One potential pathway for gaining more detailed insights into SPQ lies in the extensive collection of further SPQIs which are based on the measurement of characteristics like soil penetration resistance, soil stability, or infiltration experiments. For this study, the selection of certain SPQI values were determined by economic considerations. Furthermore, the sample size was too small to allow for a broad generalization of the outcomes regarding differences between treatments, temporal development or spatial variability. The focus was set on a detailed assessment of SPQ in the single soil profiles. Nevertheless, the soil and climate conditions are representative for a major part of the agriculturally important Pannonian region in Central Europe. Hence, the illustrated severity of soil degradation by compaction is likely to be more widespread in the region than is commonly acknowledged.

\section{CONCLUSIONS}

1. The presented observations provided a detailed insight into the soil physical quality of the observed soil profiles. The main physical problem, soil compaction, was clearly detected by multiple physical quality indicators of soil.

2. The long-term application of conservation tillage management had an influence on the main physical parameters of the soil even though this effect was often masked by spatial and temporal variability. The dominant process which modifies the physical conditions of the soil was the loosening of the soil at the lowest depth of the tilled layers and a corresponding compaction below the working depth. Nevertheless, our results suggested that even 25 years after conversion to conservation tillage, the expected improvement in the physical properties of the soil did not develop to a sufficient extent under the present climate.

\section{ACKNOWLEDGEMENTS}

We are grateful to Mr Thomas Miksch and his team from the Austrian Agency for Health and Food Safety for managing the experimental field plots.

Conflict of interest: The authors declare no conflict of interest.

\section{REFERENCES}

Abdollahi L., Munkholm L.J., and Garbout A., 2013. Tillage system and cover crop effects on soil quality: II. Pore characteristics. Soil Sci. Soc. Am. J., 78(1), 271-279.

https://doi.org/10.2136/sssaj2013.07.0302
Armindo R.A. and Wendroth O., 2016. Physical soil structure evaluation based on hydraulic energy functions. Soil Sci. Soc. Am. J., 80, 1167-1180. https://doi.org/10.2136/sssaj2016.03.0058

Armindo R.A. and Wendroth O., 2019. Alternative approach to calculate soil hydraulic-energy-indices and - functions. Geoderma, 355, 113903.

https://doi.org/10.1016/j.geoderma.2019.113903

Assouline S. and Or D., 2014. The concept of field capacity revisited: Defining intrinsic static and dynamic criteria for soil internal drainage dynamics. Water Resour. Res., 50, 4787-4802. https://doi.org/10.1002/2014wr015475

Bacher M.G., Schmidt O., Bondi G., Creamer R., and Fenton O., 2019. Comparison of soil physical quality indicators using direct and indirect data inputs derived from a combination of in-situ and ex-situ methods. Soil Sci. Soc. Am. J., 83, 5-17. https://doi.org/10.2136/sssaj2018.06.0218

Bottinelli N., Menasseri-Aubry S., Cluzeau D., and Hallaire V., 2013. Response of soil structure and hydraulic conductivity to reduced tillage and animal manure in a temperate loamy soil. Soil Use Manag., 29, 401-409.

https://doi.org/10.1111/sum.12049

Castellini M. and Ventrella D., 2012. Impact of conventional and minimum tillage on soil hydraulic conductivity in typical cropping system in Southern Italy. Soil Till. Res., 124, 47-56. https://doi.org/10.1016/j.still.2012.04.008

Castellini M., Stellacci A.M., Barca E., and Iovino M., 2019. Application of multivariate analysis techniques for selecting soil physical quality indicators: A case study in long-term field experiments in Apulia (Southern Italy). Soil Sci. Soc. Am. J., 83, 707-720.

https://doi.org/10.2136/sssaj2018.06.0223

Dane J.H. and Topp C.G. (Eds), 2002. Methods of Soil Analysis: Part 4 Physical Methods. SSSA Book Ser. 5.4. SSSA, Madison, WI. https://doi.org/10.2136/sssabookser5.4

de Jong van Lier Q., 2017. Field capacity, a valid upper limit of crop available water? Agric. Water Manag., 193, 214-220. https://doi.org/10.1016/j.agwat.2017.08.017

Dexter A.R. and Czyż E.A., 2007. Application of S-theory in the study of soil physical degradation and its consequences. Land Degrad. Develop., 18, 369-381. https://doi.org/10.1002/ldr.779

Fernández-Ugalde O., Virto I., Bescansa P., Imaz M.J., Enrique A., and Karlen D.L., 2009. No-tillage improvement of soil physical quality in calcareous, degradationprone, semiarid soils. Soil Till. Res., 106, 29-35. https://doi. org/10.1016/j.still.2009.09.012

Iovino M., Castellini M., Bagarello V., and Giordano G., 2016. Using static and dynamic indicators to evaluate soil physical quality in a sicilian area. Land Degrad. Develop., 27, 200-210. https://doi.org/10.1002/ldr.2263

Kahlon M.S., Lal R., and Ann-Varughese M., 2013. Twenty two years of tillage and mulching impacts on soil physical characteristics and carbon sequestration in Central Ohio. Soil Till. Res., 126, 151-158. https://doi.org/10.1016/j.still.2012.08.001

Koureh H.K., Asgarzadeh H., Mosaddeghi M.R., and Khodaverdiloo H., 2020. Critical values of soil physical quality indicators based on vegetative growth characteristics of spring wheat (Triticum aestivum L.). J. Soil Sci. Plant Nutr., 20, 493-506.

https://doi.org/10.1007/s42729-019-00134-8 
Kay B.D. and VandenBygaart A.J., 2002. Conservation tillage and depth stratification of porosity and soil organic matter. Soil Till. Res., 66, 107-118. https://doi.org/10.1016/s0167-1987(02)00019-3

Li Y., Li Z., Cui S., Jagadamma S., and Zhang Q., 2019. Residue retention and minimum tillage improve physical environment of the soil in croplands: A global meta-analysis. Soil Till. Res., 194, 104292. https://doi.org/10.1016/j. still.2019.06.009

Loveland P. and Webb J., 2003. Is there a critical level of organic matter in the agricultural soils of temperate regions: a review. Soil Till. Res., 70, 1-18. https://doi.org/10.1016/s0167-1987(02)00139-3

Lozano L.A., Soracco C.G., Villarreal R., Ressia J.M., Sarli G.O., and Filgueira R.R., 2019. Soil physical quality and soybean yield as affected by chiseling and subsoiling of a no-till soil. Rev. Bras. Cienc. Solo, v40:e0150160. https:// doi.org/10.1590/18069657rbcs20150160

McKenzie B.M., Tisdall J.M., and Vance W.H., 2011. Soil physical quality. In: Encyclopedia of Agrophysics. (Eds J. Gliński, J. Horabik, J. Lipiec). Encyclopedia of Earth Science Series, Springer, Dordrecht, NED. https://doi. org/10.1007/978-90-481-3585-1_10

Merante P., Dibari C., Ferrise R., Sánchet B., Iglesias A., Lesschen J.P., Kuikman P., Yeluripati J., Smith P., and Bindi M., 2017. Adopting soil organic carbon management practices in soils of varying quality: Implications and perspectives in Europe. Soil Till. Res., 165, 95-106. https://doi. org/10.1016/j.still.2016.08.001

Moreno F., Pelegrín F., Fernández J.E., and Murillo J.M., 1996. Soil physical properties, water depletion and crop development under traditional and conservation tillage in southern Spain. Soil Till. Res., 41, 25-42. https://doi.org/10.1016/ s0167-1987(96)01083-5

Olesen J.E., Trnka M., Kersebaum K.C., Skjelvag A.O., Seguin B., Peltonen-Sainio P., Rossi F., Kozyra J., and Micale F., 2011. Impacts and adaptation of European crop production systems to climate change. Eur. J. Agr., 34(2), 96-112. https://doi.org/10.1016/j.eja.2010.11.003

Parvin N., Parvage M.M., and Etana A., 2014. Effect of mouldboard ploughing and shallow tillage on sub-soil physical properties and crop performance. Soil Sci. Plant Nutr., 60, 1-7. https://doi.org/10.1080/00380768.2013.847779

Piccoli I., Furlan L., Lazzaro B., and Morari F., 2020. Examining conservation agriculture soil profiles: Outcomes from northeastern Italian silty soils combinig indirect geophysical and direct assessment methods. Eur. J. Soil Sci., 71(6). https://doi.org/10.1111/ejss.12861

Rasmussen K.J., 1999. Impact of ploughless soil tillage on yield and soil quality: A Scandinavian Review. Soil Till. Res., 53, 3-14. https://doi.org/10.1016/s0167-1987(99)00072-0
Reynolds W.D., Drury C.F., Yang X.M., Fox C.A., Tan C.S., and Zhang T.Q., 2007. Land management effects on the near-surface physical quality of a clay loam soil. Soil Till. Res., 96, 316-330. https://doi.org/10.1016/j.still.2007.07.003

Reynolds W.D., Drury C.F., Tan C.S., Fox C.A., and Yang X.M., 2009. Use of indicators and pore volume function characteristics to quantify soil physical quality. Geoderma, 152, 252-263. https://doi.org/10.1016/j.geoderma.2009.06.009

Sandén T., Spiegel H., Stüger H.-P., Schlatter N., HasImayr H.-P., Zavattaro L., Grignani C., Bechini L., D'Hose T., Molendijk L., Pecio A., Jarosz Z., Guzmán G., Vanderlinden K., Giráldez J.V., Mallast J., and ten Berge H., 2018. European long-term field experiments: knowledge gained about alternative management practices. Soil Use Manag., 34(2), 167-176. https://doi.org/10.1111/sum.12421

Schlüter S., Großmann C., Diel J., Wu G.-M., Tischer S., Deubel A., and Rücknagel J., 2018. Long-term effects of conventional and reduced tillage on soil structure, soil ecological and soil hydraulic properties. Geoderma, 332, 10-19. https://doi.org/10.1016/j.geoderma.2018.07.001

Spiegel H., Dersch G., Hösch J., and Baumgarten A., 2007. Tillage effects on soil organic carbon and nutrient availability in a long-term field experiment in Austria. Die Bodenkultur, 58, 1-4.

Thaler S., Eitzinger J., Trnka M., and Dubrovsky M., 2012. Impacts of climate change and alternative adaptation options on winter wheat yield and water productivity in a dry climate in Central Europe. J. Agr. Sci., 150, 537-555. https://doi.org/10.1017/s0021859612000093

Turek M.E., Armindo R.A., Wendroth O., and Dos Santos I., 2019. Criteria for the estimation of field capacity and their implications for the bucket type model. Eur. J. Soil Sci., 70, 278-290. https://doi.org/10.1111/ejss. 12747

Twarakavi N.K.C., Sakai M., and Simunek J., 2009. An objective analysis of the dynamic nature of field capacity. Water Resour.Res.,45, 1-9.https://doi.org/10.1029/2009wr007944

van Genuchten M.Th., 1980. A closed-form equation for predicting the hydraulic conductivity of unsaturated soils. Soil Sci. Soc. Am. J., 44, 892-898. https://doi.org/10.2136/sssaj1980. 03615995004400050002x

Weninger T., Kreiselmeier J., Chandrasekhar P., Julich S., Feger K.-H., Schwärzel K., Bodner G., and Schwen A., 2019. Effects of tillage intensity on pore system and physical quality of silt-textured soils detected by multiple methods. Soil Res., 57, 703-711. https://doi.org/10.1071/ $\operatorname{sr} 18347$ 